\title{
Does treatment with sub-lingual allergen-specific immunotherapy reduce adenoid size and improve quality of life among Egyptian children?
}

Nermine Nabil Nermine ${ }^{1}$, Mohab Mohamed Shehata², Yasser Taha Madian², Mohamed Hussien BadrEldin ${ }^{3}$

${ }^{1}$ Microbiology and Immunology Department, Faculty of Medicine, Suez Canal
University, Ismailia, Egypt
${ }^{2}$ Department of Otolaryngology, Port Fouad Hospital, Port Fouad, Egypt
${ }^{3}$ Otolaryngology Department, Faculty of Medicine, Suez Canal University, Ismailia, Egypt

Submitted: 1 February 2019

Accepted: 5 May 2019

Arch Med Sci Civil Dis 2019; 4: e51-e57

DOI: https://doi.org/10.5114/amscd.2019.86741

Copyright (c) 2019 Termedia \& Banach

\author{
Corresponding author: \\ Nermine Nabil Nermine \\ Microbiology and \\ Immunology Department \\ Faculty of Medicine \\ Suez Canal University \\ Ismailia, Egypt \\ Phone: 002/01224117033 \\ E-mail: nermine76@hotmail. \\ com
}

\begin{abstract}
Introduction: Adenoidal hypertrophy is a paediatric problem. Adenoidectomy contributes to post-operative complications. Allergic rhinitis is a major health problem. Its prevalence in Egypt and the Middle East is up to $9 \%$. The aim of the present study was to evaluate the effect of sub-lingual immunotherapy on adenoid size and/or quality of life among children suffering from adenoid hypertrophy with allergic rhinitis in Suez Canal University Hospital. Material and methods: Forty-six children suffering from adenoid hypertrophy and allergic rhinitis were recruited for this purpose. Skin prick test was administered to identify the causative allergen. All patients received sub-lingual immunotherapy. Lateral X-ray, serum total immunoglobulin E, symptoms, and sign score were recorded for all patients before and after the treatment. Results: The nasal symptoms and adenoidal size of the examined patients were significantly decreased after immunotherapy was applied, and thus there was an improvement in the quality of life among those patients.

Conclusions: It was concluded that sub-lingual immunotherapy was an alternative treatment of adenoidectomy in children with moderate adenoid hypertrophy with allergic rhinitis. Surgical treatment for children who suffer from severe adenoid hypertrophy with allergic rhinitis could not be considered as obligatory because medical treatment has no effect on the size of adenoids nor on quality of life.
\end{abstract}

Key words: adenoid hypertrophy, allergic rhinitis, sub-lingual immunotherapy, Egypt.

\section{Introduction}

Adenoidal hypertrophy $(\mathrm{AH})$ is a paediatric problem resulting from antigenic stimulation due to severe or chronic inflammation, leading to obstruction of the nasal passages, Eustachian tubes, and blocking the clearance of nasal mucus [1]. Anatomically, the adenoid size reaches its maximum size by the age of 6 years, then gradually decreases at the age of 9 years [2].

Adenoidectomy is considered the typical modality treatment in those patients. Although it plays an important role in relieving obstructive 
symptoms, it may lead to some serious complications, such as bleeding (4-5\%) and postoperative respiratory compromise (27\%) [3].

Allergic rhinitis (AR) is a major health problem that affects 10 to $40 \%$ of the global population [4, 5]. In terms of allergic rhinitis and its impact on asthma (ARIA), AR is seen as increasing the production of immunoglobulin (Ig) E of the mucosa after exposure to the allergen, leading to sneezing, nasal obstruction, and mucus discharge [4-6]. The prevalence of AR in Egypt and the Middle East is up to $9 \%$ [7].

The wide spread of indoor and outdoor allergens and the small chances of avoiding them raise the appearance and efficacy of allergen-specific immunotherapy (ASIT), despite its effects on the immune system [8].

Sub-lingual immunotherapy (SLIT) stimulates T-helper (TH) 1 and the regulatory T-cells to migrate into the bloodstream and mucosa after the production of interferon $\gamma(\mathrm{IFN}-\gamma)$ and interleukin (IL)-10 a few days after its administration [9].

The safety, ease of administration, patient compliance, and reduced side effects of SLIT (manifested in oral pruritus and throat irritation) increase its usage worldwide [8].

The aim of the current study was to evaluate the effect of SLIT on adenoid size and/or quality of life (QoL) among children suffering from adenoid hypertrophy with AR in Suez Canal University Hospital.

Table I. Type of allergens among the studied patients $(n=46)$

\begin{tabular}{|lcc|}
\hline Allergen & \multicolumn{2}{c|}{ Studied population $(N=46)$} \\
\cline { 2 - 3 } & $\boldsymbol{N}$ & $\%$ \\
\hline HDM & 34 & 74.0 \\
\hline HD & 42 & 52.2 \\
\hline Tobacco & 14 & 30.4 \\
\hline Aspirin & 8 & 17.4 \\
\hline Latex & 8 & 17.4 \\
\hline Cockroach & 8 & 17.4 \\
\hline Dog epithelium & 6 & 13.0 \\
\hline Cat epithelium & 6 & 13.0 \\
\hline Timothy grass & 6 & 13.0 \\
\hline Aspergillus fumigatus & 4 & 8.7 \\
\hline Banana & 4 & 8.7 \\
\hline Bermuda grass & 4 & 8.7 \\
\hline Mixed pollen & 4 & 8.7 \\
\hline Soya bean & 4 & 8.7 \\
\hline
\end{tabular}

\section{Material and methods}

This study was conducted at the Otolaryngology Department in the Suez Canal University Hospital affiliated to the Faculty of Medicine in Ismailia in Egypt from June 2013 to March 2016. The studied population was 46 children of both sexes, with age range from four to nine years, suffering from $\mathrm{AH}$ and AR, with no previous history of ASIT administration, and with exclusion of those having: anaphylaxis (i.e. after the first dose of immunotherapy), chronic infections, immunodeficiency diseases, asthma uncontrolled by pharmacotherapy, and/or irreversible airway obstruction and malignancy. Severity of nasal and adenoid symptoms were assessed [10, 11], as well as full head and neck- examinations, anterior and posterior rhinoscopy, cold mirror test, nasopharyngoscopy, and radiological assessment for of $\mathrm{AH}$ and $\mathrm{AR}$ were conducted.

The adenoidal nasopharyngeal ratio was measured by detecting many landmarks on the nasopharyngeal X-ray as follows:

- Q: the point of maximal convexity of the adenoid shadow,

- O: a line running tangential to the basiocciput,

- T: the posterior border of the hard palate,

- X: the antero-inferior aspect of the spheno-basi-occipital synchondrosis,

- N: the distance between $T$ and $X$,

$-\mathrm{A}$ : a line drawn from $\mathrm{Q}$ to $\mathrm{X}$,

$-\mathrm{N}$ : a line drawn from $T$ to $X$.

The degree of nasopharyngeal airway obstruction by the adenoid was classified and scored as follows [12]:

- normal (AN ratio $<0.50)=0$ points,

- mild (AN ratio 0.50-0.62) = 1 point,

- moderate (AN ratio 0.63-0.75) = 2 points,

- severe (AN ratio 0.76-0.88) $=3$ points.

Skin prick test for the allergens of house dust (HD), house dust mites (HDM), cockroach, mixed pollen, mixed feathers, Aspergillus fumigatus, Timothy grass, sheep wool, hay dust, latex, tobacco, mixed mould, dog epithelium, cat epithelium, Bermuda grass, Alternaria tenuis, milk, banana, egg, strawberry, Salonecea, mixed fish, mango, maize, soy-bean, wheat, cocoa, and mixed nuts was performed.

All patients received SLIT drops for five months according to skin reactivity. Allergen extracts were serially diluted to five concentrations according to weight/volume $(\mathrm{w} / \mathrm{v})$ ratio into $(1: 50000 \mathrm{w} / \mathrm{v}$, $1: 5000 \mathrm{w} / \mathrm{v}, 1: 500 \mathrm{w} / \mathrm{v}, 1: 50 \mathrm{w} / \mathrm{v}$, and $1: 5 \mathrm{w} / \mathrm{v})$.

Lateral $X$-ray, serum total IgE, and symptoms and signs severity score were done for all patients before and after five months of treatment.

QoL assessment was conducted for all patients, using a seven-point scale for severity of allergic rhinitis on sleep patterns at night, work performance, and social and/or recreational activities. 


\section{Ethical considerations}

The study work had the approval from the Ethics Committee of the Faculty of Medicine, Suez Canal University (FOMSCU) in Ismailia, Egypt.

\section{Statistical analysis}

The gathered data were processed using SPSS version 20 (SPSS Inc., Chicago, IL, USA). Quantitative data were expressed as means \pm SD, while qualitative data were expressed as numbers and percentages (\%). Student's $t$-test was used to test significance of difference for quantitative variables. A probability value of $p<0.05$ was considered statistically significant.

\section{Results}

The demographic characteristics of the children in this study showed an age range from 4 to
9 years with a mean $5.6 \pm 1.7$ years and with a predominance of female patients over male patients (65.2\% vs. $34.8 \%$, respectively) (Table I).

The nasal and non-nasal symptoms among the studied population showed statistical improvement before and after immunotherapy and are represented in Tables II-IV.

For the effect of medication on nasal and non-nasal symptoms before immunotherapy, we found that no medications had been used in nine and 17 cases, respectively, and for the moderate relief, it was four and two cases, respectively. Also, the effect of immunotherapy could substantially decrease the serum levels of total IgE after its administration for months.

Table $V$ shows that changes occurred in the size of adenoids among the studied population after immunotherapy in comparison with its size before immunotherapy. These were expressed in numbers and percentages including the mean and

Table II. Nasal symptoms among the studied patients before and after treatment $(n=46)$

\begin{tabular}{|c|c|c|c|c|c|}
\hline \multirow[t]{2}{*}{ Variables } & \multicolumn{2}{|c|}{ Before } & \multicolumn{2}{|c|}{ After } & \multirow[t]{2}{*}{$P$-value } \\
\hline & $N$ & $\%$ & $N$ & $\%$ & \\
\hline Sneezing: & & & & & $<0.0001^{\star *}$ \\
\hline None & 8 & 17.4 & 18 & 39.1 & \\
\hline Mild & 18 & 39.1 & 20 & 43.5 & \\
\hline Moderate & 16 & 34.8 & 6 & 13.0 & \\
\hline Severe & 4 & 8.7 & 2 & 4.3 & \\
\hline Runny nose: & & & & & $0.0002^{\star *}$ \\
\hline None & 18 & 39.1 & 30 & 65.2 & \\
\hline Mild & 22 & 47.8 & 12 & 26.1 & \\
\hline Moderate & 6 & 13.0 & 4 & 8.7 & \\
\hline Congestion: & & & & & $0.015^{\star}$ \\
\hline None & 16 & 34.8 & 24 & 52.2 & \\
\hline Mild & 20 & 43.5 & 16 & 34.8 & \\
\hline Moderate & 10 & 21.7 & 6 & 13.0 & \\
\hline Itching: & & & & & $0.009^{\star *}$ \\
\hline None & 14 & 30.4 & 22 & 47.8 & \\
\hline Mild & 20 & 43.5 & 20 & 43.5 & \\
\hline Moderate & 12 & 26.1 & 4 & 8.7 & \\
\hline Post nasal: & & & & & 0.37 \\
\hline None & 16 & 34.8 & 22 & 47.8 & \\
\hline Mild & 20 & 43.5 & 14 & 30.4 & \\
\hline Moderate & 6 & 13.0 & 8 & 17.4 & \\
\hline Severe & 4 & 8.7 & 2 & 4.3 & \\
\hline
\end{tabular}

*Significant $p$-value $<0.05,{ }^{*}$ highly significant $p$-value $<0.01$. 
Table III. Non-nasal symptoms among the studied patients $(n=46)$

\begin{tabular}{|c|c|c|c|c|c|}
\hline \multirow[t]{2}{*}{ Variables } & \multicolumn{2}{|c|}{ Before } & \multicolumn{2}{|c|}{ After } & \multirow[t]{2}{*}{$P$-value } \\
\hline & $N$ & $\%$ & $N$ & $\%$ & \\
\hline Eye symptoms: & & & & & $0.030^{*}$ \\
\hline None & 32 & 69.6 & 38 & 82.6 & \\
\hline Mild & 12 & 26.1 & 8 & 17.4 & \\
\hline Moderate & 2 & 4.3 & 0 & 0.0 & \\
\hline Throat symptoms: & & & & & $0.05^{\star}$ \\
\hline None & 26 & 56.5 & 32 & 69.6 & \\
\hline Mild & 14 & 30.4 & 10 & 21.7 & \\
\hline Moderate & 6 & 13.0 & 4 & 8.7 & \\
\hline Chronic cough: & & & & & $0.002^{* *}$ \\
\hline None & 18 & 39.1 & 28 & 60.9 & \\
\hline Mild & 20 & 43.5 & 14 & 30.4 & \\
\hline Moderate & 8 & 17.4 & 4 & 8.7 & \\
\hline Ear symptoms: & & & & & 0.18 \\
\hline None & 28 & 60.9 & 32 & 69.6 & \\
\hline Mild & 12 & 26.1 & 12 & 26.1 & \\
\hline Moderate & 6 & 13.0 & 2 & 4.3 & \\
\hline Headache: & & & & & $0.030^{*}$ \\
\hline None & 32 & 69.6 & 38 & 82.6 & \\
\hline Mild & 14 & 30.4 & 8 & 17.4 & \\
\hline
\end{tabular}

*Significant $p$-value $<0.05,{ }^{* *}$ highly significant $p$-value $<0.01$.

Table IV. Total nasal and non-nasal symptoms among the studied patients before and after immunotherapy $(n=46)$

\begin{tabular}{|c|c|c|c|c|c|}
\hline \multirow[t]{2}{*}{ Total symptoms } & \multicolumn{2}{|c|}{ Before } & \multicolumn{2}{|c|}{ After } & \multirow[t]{2}{*}{$P$-value } \\
\hline & $N$ & $\%$ & $N$ & $\%$ & \\
\hline None & 18 & 0.0 & 0 & 39.1 & $0.0007^{* *}$ \\
\hline Mild & 38 & 82.6 & 20 & 43.6 & \\
\hline Moderate & 4 & 8.7 & 6 & 13.0 & \\
\hline Severe & 4 & 8.7 & 2 & 4.3 & \\
\hline
\end{tabular}

**Highly significant $p$-value $<0.01$.

Table V. Adenoid size among the studied population before and after immunotherapy $(n=46)$

\begin{tabular}{|c|c|c|c|c|c|}
\hline \multirow[t]{2}{*}{ Adenoid size } & \multicolumn{2}{|c|}{ Before } & \multicolumn{2}{|c|}{ After } & \multirow[t]{2}{*}{$P$-value } \\
\hline & $N$ & $\%$ & $N$ & $\%$ & \\
\hline AN $0.62>0.75$ & 30 & 65.2 & 28 & 60.9 & \\
\hline AN $\geq 0.75$ & 16 & 34.8 & 18 & 39.1 & \\
\hline Mean size (SD) & $0.70(0.06)$ & & $0.69(0.06)$ & & $0.009^{* *}$ \\
\hline
\end{tabular}

${ }^{*}$ Highly significant $p$-value $<0.01, S D-$ standard deviation. 
standard deviation as well as the statistical significance test and the $p$-value. The size of adenoid was measured by the adenoidal nasopharyngeal ratio (AN), as explained in the materials and methods section.

Also, we found that the effect of immunotherapy caused moderate improvement of symptoms in 30 cases and severe improvement in 16 , out of a total of 46, with a significant relationship ( $p<$ 0.0001) (Table VI). Table VII shows that there was a statistically significant decrease of serum level of total IgE after immunotherapy. The relation between quality of life (QOL) and severity of adenoidal hypertrophy among the studied patients before and after immunotherapy presented in Table VIII.

\section{Discussion}

Because the adenoids are located on the roof of nasopharyngeal cavity, this permits close contact with allergens that settle onto the mucous membrane [13]. The early exposure to allergens in childhood permits the development of natural acquired immunity [14].

This study was conducted on 46 children with an age range of 4-9 years because $\mathrm{AH}$ increases during this span and declines by the age of 12 years. This copes with Somayajj et al. [15] and Evcimik et al. [16] who conducted their study on the same age range.

In the present study, the most common allergens found in these children were, in descending order, $\operatorname{HDM}$ (74.0\%), HD (52.2\%), tobacco

Table VI. The clinical rating scale for adenoidal symptoms among the studied patients before and after immunotherapy $(n=46)$

\begin{tabular}{|c|c|c|c|c|c|}
\hline \multirow[t]{2}{*}{ Variables } & \multicolumn{2}{|c|}{ Before } & \multicolumn{2}{|c|}{ After } & \multirow[t]{2}{*}{$P$-value } \\
\hline & $N$ & $\%$ & $N$ & $\%$ & \\
\hline Snoring: & & & & & $0.0002^{* *}$ \\
\hline Absent & 0 & 0.0 & 6 & 13.1 & \\
\hline Present on a few occasions during sleep & 0 & 0.0 & 16 & 34.8 & \\
\hline Present whenever asleep & 28 & 60.9 & 10 & 21.7 & \\
\hline Present whenever asleep or awake & 18 & 39.1 & 14 & 30.4 & \\
\hline Mouth breathing: & & & & & $<0.0001^{\star *}$ \\
\hline Absent & 0 & 0.0 & 8 & 17.4 & \\
\hline Present on a few occasions during sleep & 8 & 17.4 & 16 & 34.8 & \\
\hline Present whenever asleep & 30 & 65.2 & 14 & 30.4 & \\
\hline Present whenever asleep or awake & 8 & 17.4 & 8 & 17.4 & \\
\hline Obstructive breathing during asleep: & & & & & 0.17 \\
\hline Absent & 30 & 65.2 & 34 & 73.9 & \\
\hline Present on a few occasions during sleep & 12 & 26.1 & 8 & 17.4 & \\
\hline Present, fewer than 5episodes daily & 4 & 8.7 & 4 & 8.7 & \\
\hline Present, more than 5 episodes daily & 0 & 0 & 0 & 0 & \\
\hline
\end{tabular}

**Highly significant $p$-value $<0.01$.

Table VII. Percentages of total IgE levels among the studied patients before and after immunotherapy $(n=46)$

\begin{tabular}{|c|c|c|c|c|c|}
\hline \multirow[t]{2}{*}{ Total IgE } & \multicolumn{2}{|c|}{ Before } & \multicolumn{2}{|c|}{ After } & \multirow[t]{2}{*}{$P$-value } \\
\hline & $N$ & $\%$ & $N$ & $\%$ & \\
\hline ULN & 5 & 21.8 & 6 & 26.1 & 0.51 \\
\hline 1-2-fold ULN & 7 & 30.4 & 11 & 47.8 & $0.009^{* *}$ \\
\hline 3-4-fold ULN & 4 & 17.4 & 2 & 8.7 & 0.1 \\
\hline > 4-fold ULN & 7 & 30.4 & 4 & 17.4 & $0.03^{*}$ \\
\hline
\end{tabular}

${ }^{*}$ Significant $p$-value $<0.05,{ }^{* *}$ highly significant $p$-value $<0.01$, ULN-upper limit of normal. 
Table VIII. The relation between quality of life $(\mathrm{Q} o \mathrm{~L})$ and severity of adenoidal hypertrophy among the studied patients before and after immunotherapy $(n=46)$

\begin{tabular}{|c|c|c|c|c|c|c|c|c|c|}
\hline \multirow[t]{3}{*}{ Variables } & \multicolumn{4}{|c|}{ Moderate $(n=30)$} & \multicolumn{4}{|c|}{ Severe $(n=16)$} & \multirow[t]{3}{*}{$P$-value } \\
\hline & \multicolumn{2}{|c|}{ Before } & \multicolumn{2}{|c|}{ After } & \multicolumn{2}{|c|}{ Before } & \multicolumn{2}{|c|}{ After } & \\
\hline & $N$ & $\%$ & $N$ & $\%$ & $N$ & $\%$ & $N$ & $\%$ & \\
\hline QOL terribly affected & 0 & 0.0 & 0 & 0.0 & 4 & 25.0 & 4 & 25.0 & $<0.0001^{\star *}$ \\
\hline QOL affected almost all time & 0 & 0.0 & 0 & 0.0 & 6 & 37.5 & 4 & 25.0 & \\
\hline Quality of life often affected & 2 & 6.7 & 2 & 6.7 & 2 & 12.5 & 2 & 12.5 & \\
\hline $\begin{array}{l}\text { QOL occasionally affected but } \\
\text { tolerable }\end{array}$ & 14 & 46.6 & 10 & 33.3 & 4 & 25.0 & 4 & 25.0 & \\
\hline QOL hardly affected & 12 & 40.0 & 2 & 6.7 & 0 & 0.0 & 2 & 12.5 & \\
\hline Quality of life mildly affected & 2 & 6.7 & 10 & 33.3 & 0 & 0.0 & 0 & 0.0 & \\
\hline Excellent QOL & 0 & 0.0 & 6 & 20.0 & 0 & 0.0 & 0 & 0.0 & \\
\hline
\end{tabular}

${ }^{* *}$ Highly significant $p$-value $<0.01$.

(30.4\%), aspirin (17.4\%), latex (17.4\%), cockroach $(17.4 \%)$, dog epithelium $(13.0 \%)$, cat epithelium (13.0\%), and Timothy grass (13.0\%). The abundance of HDM in Egypt is attributed to the geographic situation and the climatic condition of our country, as revealed by Kenawy et al. [17] in their research - HDM is the focus allergen in their work.

SLIT stimulate the TH 1 and regulatory T-cells to migrate into the bloodstream and mucosa after the production of IFN- $\gamma$ and IL-10 a few days after its administration [9]. It remains the only aetiological treatment for allergic diseases [18]. In this study, we found that SLIT induced reduction of the serum level of total Ig E, the severity of sneezing, running nose, congestion, itching, eye symptoms, throat symptoms, chronic cough, and headache after 5 months of its administration as well as improvement in QoL among the treated children due to the alteration of immune response. Several studies were in consistent with ours, such as Niederberger [19], Chang et al. [20], and Rolinck-Werninghaus et al. [21].

The ordinary medical treatment usually improves the symptoms of $\mathrm{AH}$ as well as adenoid size. Many meta-analyses conducted in this area, such as the one by Cengel and Akyol [22], concur that mometasone decreases the adenoid dimensions and improves related symptoms in the long term.

For intranasal budesonide, Gozal and Gozal [23] stated that its usage with a dose of $32 \mu \mathrm{g} /$ nostril once daily in children with mild obstructive sleep apnoea syndrome effectively reduced the apnoea-hypopnoea index and adenoid dimensions measured (by lateral X-rays) and polysomnographies (PSG). Also, this effect persisted for at least 8 weeks after cessation of therapy.

Jung et al. [24] concluded that children with sleep disorders in breathing due to $\mathrm{AH}$ could be effectively treated with a 4-week course of mometasone furoate. In a systemic review, six out of seven studies showed that the treatment with nasal corticosteroids improved nasal obstructive symptoms and reduced adenoid size, and its effect was sustained for a long time [25].

Meanwhile, the views regarding beclomethasone nasal spray are completely different from the other nasal sprays; Lepcha et al. [26] and others indicated that there was no significant change in nasal symptoms nor in the adenoidal size in the general paediatric population.

In this study, regarding adenoid size, we reported that there was a minimal significant decrease from $0.70 \mathrm{~mm}$ before to $0.69 \mathrm{~mm}$ after SLIT, while the clinical rating scale for adenoidal symptoms including snoring, mouth breathing, and obstructive breathing during sleep showed significant improvement. The improvement of these symptoms can be explained in terms of the amelioration of $A R$, while the minimal change of adenoid size can be attributed to the short period of treatment. Additionally, the QoL was remarkable in children with moderate $\mathrm{AH}$ compared to those who suffered from severe hypertrophy.

AR influences the occurrence of $\mathrm{AH}$; it is considered an important risk factor in children allergic to HDM when compared with normal one [27].

It is very clear that there is similarity of clinical symptoms of AR and adenoid hypertrophy. Thus, it is important that the allergists and otolaryngologists take account of the allergic background of AR and adenoid hypertrophy [28].

In conclusion, surgical treatment for children who suffer from severe AH with AR is obligatory, because medical treatment has no effect on adenoid size or QoL, while sub-lingual immunotherapy is recommended as an alternative treatment of adenoidectomy in children with moderate ad- 
enoid hypertrophy with AR because QoL shows significant improvement in such cases.

\section{Conflict of interest}

The authors declare no conflict of interest.

\section{References}

1. Kenna M, Amin A. Anatomy and physiology of the oral cavity. In: Ballenger's Otorhinolaryngology Head and Neck Surgery. Mc-Graw Hill 2009; 769-74.

2. Hellings P, Fokkens W. Allergic rhinitis and its impact on otorhinolaryngology. J Allergy 2006; 61: 656-64.

3. Stuck B, Gotte K, Windfuhr J, Genzwürker H, Schroten H, Tenenbaum T. Tonsillectomy in children. J Dtsch Arztebl Int 2008; 105: 852-60.

4. Bousquet J, Van Cauwenberge P, Khaltaev N. Allergic rhinitis and its impact on asthma. J Allergy Clin Immunol 2001; 108 (5 Suppl): S147-334.

5. Wilson K, Spector M, Orlandi R. Types of rhinitis. J Otolaryngol Clin North Am 2011; 44: 549-59.

6. Natt R, Karkos P, Natt D, Theochari E, Karkanevatos A. Treatment trends in allergic rhinitis and asthma: a British ENT survey. BMC Ear Nose Throat Disord 2011; 11: 11-3.

7. Abdulrahman $\mathrm{H}$, Hadi U, Tarraf $\mathrm{H}$, et al. Nasal allergies in the Middle Eastern population: results from the "Allergies in Middle East Survey”. J Am J Rhinol Allergy 2012; 26: 3-23.

8. Moingeon P, Mascarell L. Induction of tolerance via the sublingual route: mechanisms and applications. J Clin Dev Immunol 2012; 2012: 623474.

9. Moingeon P. Update on immune mechanisms associated with sublingual immunotherapy: practical implications for the clinician. J Allergy Clin Immunol Pract 2013; 1: 228-41.

10. Spector S, Nicklas R, Chapman J, et al. Symptom severity assessment of allergic rhinitis: part 1. J Ann Allergy Asthma Immunol 2003; 91: 105-14.

11. Orji F, Ezeanolue B. Evaluation of adenoidal obstruction in children: clinical symptoms compared with roentgenographic assessment. J Laryngol Otol 2008; 122: 1201-5.

12. Egeli E, Oghan F, Ozturk O, Harputluoglu U, Yazici B. Measuring the correlation between adenoidal-nasopharyngeal ratio (AN ratio) and tympanogram in children. J Pediatr Otorhinolaryngol 2005; 69: 229-33.

13. Winther B, Innes D. The human adenoid - a morphologic study. J Arch Otolaryngol Head Neck Surg 1994; 120: 144-9.

14. Wysocka J, Hassmann E, Lipska A, Musiatowicz M. Naive and memory $T$ cells in hypertrophied adenoids in children according to age. J Int J Pediatr Otorhinolaryngol 2003; 67: 237-41.

15. Somayaj G, Rajeshwari A, Jain M. Significance of adenoid nasopharyngeal ratio in the assessment of adenoid hypertrophy in children. J Res Otolaryngol 2004; 1: 1-5.

16. Evcimik M, Dogru M, Ciri A, Nepesov M. Adenoid hypertrophy in children with allergic disease and influential factors. J Int J Pediatr Otorhinolaryngol 2015; 79: 694-7.

17. Kenawy M, Awad A, El-Shafei A, Helmi N, AbdelHamid Y, El-Zohery Y. House dust mites associated with the asthmatic patientsin some houses of Cairo, A.R. Egypt. J Egypt Acad J Biolog Sci 2012; 4: 1-5.

18. Mailhol C, Didier A. Allergen-specific immunotherapy in the treatment of pollen allergy. J Rev Mal Respir 2013; 30: $142-51$.
19. Niederberger V. Allergen-specific immunotherapy. J Immunol Lett 2009; 122: 131-3.

20. Chang H, Han D, Mo J. Early compliance and efficacy of sublingual immunotherapy in patients with allergic rhinitis for house dust mites. J Clin Exp Otorhinolaryngol 2009; 2: 136-40.

21. Rolinck-Werninghaus $\mathrm{C}$, Wolf $\mathrm{H}$, Liebke $\mathrm{C}$, et al. A prospective, randomized, double-blind, placebo-controlled multi-centre study on the efficacy and safety of sublingual immunotherapy (SLIT) in children with seasonal allergic rhinoconjunctivitis to grass pollen. J Allergy 2004; 59: 1285-93.

22. Cengel $S$, Akyol M. The role of topical nasal steroids in the treatment of children with otitis media with effusion and/or adenoid hypertrophy. J Pediatr Otorhinolaryngol 2006; 70: 639-45.

23. Gozal L, Gozal D. Intranasal budesonide treatment for children with mild obstructive sleep apnea syndrome. J Pediatrics 2008; 122: 149-55.

24. Jung Y, Kim H, Min J, Dhong H, Chung S. Role of intranasal topical steroid in pediatric sleep disordered breathing and influence of allergy, sinusitis, and obesity on treatment outcome. J Clin Exp Otorhinolaryngol 2011; 4: 27-32.

25. Chadha N, Zhang L, Mendoza-Sassi R, César J. Using nasal steroids to treat nasal obstruction caused by adenoid hypertrophy: does it work? J Otolaryngol Head Neck Surg 2009; 140: 139-47.

26. Lepcha A, Kurien M, Job A, Jeyaseelan L, Thomasc K. Chronic adenoid hypertrophy in children - is steroid nasal spray beneficial? J Indian J Otolaryngol Head Neck Surg 2002; 54: 280-4.

27. Modrzyński M, Rapiejko P. The incidence of adenoid hypertrophy in allergic diseases. I Case Rep Clin Pract Rev 2004; 5: 487-91.

28. Modrzynski M, Zawisza E. An analysis of the incidence of adenoid hypertrophy in allergic children. J Int J Pediatr Otolaringol 2007; 71: 713-9. 